http://jmscr.igmpublication.org/home/

ISSN (e)-2347-176x ISSN (p) 2455-0450

crossref DOI: https://dx.doi.org/10.18535/jmscr/v8i5.78

Journal Of Medical Science And Clinical Research

\title{
Research Paper \\ Factors Associated with Occupational Hazards in the Integrated Craft Production Centers Kigali, Rwanda
}

\author{
Authors \\ MUNYANEZA Abel ${ }^{1}$, John Gacohi ${ }^{1}$, Daniel Mokaya ${ }^{1}$ \\ ${ }^{1}$ School of Public Health, Jomo Kenyatta University of Agriculture and Technology, Kenya
}

\begin{abstract}
This study determined the prevalence of occupational health hazards and associated factors among Integrated Craft Production Centers in Rwanda. Adopted a cross-sectional design involving both qualitative and quantitative data collection approaches. Where 276 workers selected systematically participated in the study. Data were collected using semi structured questionnaires, a focus group discussion with guide and an observational checklist. Among 276 study participant $97.1 \%$ are exposed to occupational hazards mainly Noise 93.8\%, Fall of material $89.9 \%$ and use of sharp equipment 89,5\%. Moreover, factors associated with occurrence of occupational hazards were poor infrastructure $(P=0.005)$, lack of complete Personal Protective Equipment $(P=0.000)$, little knowledge on health and safety measures $(P=0.0014)$, negligence of safety procedure $(P=0.003)$, Distraction with other issues during work $(P=0.004)$, Lack of skills and experience $(P=0.003)$ and Lack of knowledge of job responsibilities $(P=0.028)$. By Conclusion, workers are exposed to occupational hazards, thus it is necessary to establish occupational health and safety trainings and awareness campaign.

Keywords: Factors, Health, Occupational Safety and Health, Occupational Hazards.
\end{abstract}

\section{Introduction}

Worldwide it is estimated that 2.8 billion employees spend one third of their lifetime at work, this explain why improvement of working environment should be taken as the important human right $^{1}$. Even though the increase of occupational accidents and diseases attracted attention in recent years, still work-related diseases and occupational injuries cause over 2.78 million deaths annually all-over the word ${ }^{2}$. They are attributed to poor working conditions and inattention to proper occupational health and safety practices especially in developing countries ${ }^{1}$ caused by different political, economic and social factors $^{3}$ as well as rapid industrialization and technological development. ${ }^{1}$

The control of occupational hazards by making work environment safer is successful when there is collaboration between the government, employers and employees through consideration of medical, engineering and legislative interventions $^{1,4}$.

Occupational health accidents and work related diseases has impact on the Gross Domestic Product of countries where its cost varies between 1.8 to $6 \%{ }^{5}$. Researches show that $3.2 \%$ workers in developed countries reported encountering work accidents ${ }^{6}$. England recorded 1.4 million 
work related ill health cases, 147 fatal injuries and 69208 non-fatal injuries in $2019^{7}$. The situation is worse in developing countries that have more than $80 \%$ of global occupational diseases and injuries ${ }^{1}$. Since occupational accidents cause a great number of death and injuries, different countries have started prioritizing health and safety of workers through prevention of accidents and work related diseases. ${ }^{8}$ In addition, increasing awareness of the adverse effects of occupational accidents and diseases on workers has led to the improving the enforcement of preventive measures to combat work risks. ${ }^{9}$

Even though the government of Rwanda has put a lot of effort in the promotion of descent work and assuring safe workplaces for workers through setting laws, standards, guidelines and different programs designed to promote Occupational Safety and Health. It was evident that they was increase of work fatalities since their number in 2012 were seven times greater than their number in the 2007 in the same way the number of injuries in the year 2012 was almost four times greater than their number in $2007 .{ }^{10}$ In addition, findings of occupational health and safety studies conducted in Rwanda showed that there is high prevalence of exposure to work hazards in different professions. ${ }^{4,11}$ Thus, the study was conducted to determine the types of occupational hazards, their prevalence as well as determining factors associated with occupational health hazards among workers in Integrated Craft Production Centers in Kigali, Rwanda. These are centers created by the government of Rwanda with the purpose of establishing standardized and modern business to accommodate local craftsmen and artisans. ${ }^{12}$

\section{Methods}

Study Design: The study adopted a crosssectional descriptive study design using both qualitative and quantitative methods of data collection.

Study Area: The study was conducted in three Integrated Craft Production Centers (ICPC) located in Kigali city, Rwanda that are Nyarugenge ICPC in Nyarugenge District, Gisozi ICPC in Nyarugenge District and Gahanga ICPC in Kicukiro District. In these Integrated Craft Production Centers at the time of study, they were eight hundred ninety one (891) employees, distributed into different activities that are Carpentry, Welding and Craftsmen.

Data Collection: Data collection done by using interviewer-administered questionnaires, observation checklist and focused group discussion with guide.

Questionnaires helped to collect different types of data including social demographic characteristics of respondent, data related to the independent variables as well as data related to dependent variables.

The instrument validity was measured by using Content Validity Index determined by two experts in the field of study who ranked questions by giving marks on suggesting whether the question is appropriate or Inappropriate, the researcher gathered responses of experts and computed content validity index (CVI) CVI 79/90 $=0.87$. Moreover, experts assisted in rephrasing of the questions

The study instrument reliability was obtained by conducting a pilot test of the survey Questionnaires at Gahanga Integrated Craft Production Center located in Kicukiro District, City of Kigali. After piloting, necessary changes were made to the questionnaire to make sure it is well adapted to the study participants and final approval of the instrument. The researcher computed results by using the Cronbach's Alpha by using SPSS version 21 test results of sixty-six (66) items was 0.7

Sample Size Estimation: The study used Yamane formula to calculate the sample size

$$
\mathrm{n}=\frac{N}{1+N(e) 2}
$$

n: Sample size, N: Total population size 891,

(e) The level of precision given as $5 \%=0.05$

By applying the above formula, the sample size was two hundred seventy six (276) workers, the response late was $100 \%$. 
To work out sample size for each stratum in the Integrated Craft Production Centers, the study used proportionate stratification sampling by weight to calculate specific sample sizes.

By using the formula $\mathrm{nh}=(\mathrm{Nh} / \mathrm{N}) * \mathrm{n}$

Where:

nh represent the sample size for stratum h. Nh represent the population size for stratum $h$,

$\mathbf{N}$ represent total population size. $\mathrm{n}$ represent total sample size.

Data Analysis: The data generated from the study was analysed by using SPSS (version 21). Descriptive statistics was usedto determine the profile of the respondents and characterise occupational hazards; they were presented in form of frequency as well as percentage distribution by using tables. While chi-square test was used to determine the association between variables that are statistically significant at $\mathrm{P}$ - value $<0.05$

Ethical Considerations: The researcher obtained authorization to conduct research from the Jomo Kenyatta University of Agriculture and Technology (JKUAT) ethical review board. While the consent to collect data was given by individual participant, after getting the written permission from the Integrated Craft Production Management leaders. The participation in the study was voluntary and the researcher insured that information given were kept strictly confidential.

\section{Results}

Table 1: Socio-demographic characteristics of respondents

\begin{tabular}{|c|c|c|}
\hline $\begin{array}{l}\text { Respondent's } \\
\text { Characteristics }\end{array}$ & Frequencies & percentage \\
\hline \multicolumn{3}{|l|}{ Sex } \\
\hline Male & 271 & 98.2 \\
\hline Female & 5 & 1.8 \\
\hline \multicolumn{3}{|l|}{ Age } \\
\hline$[18-30]$ & 124 & 44.9 \\
\hline [31-40] & 125 & 45.3 \\
\hline$[41-50]$ & 27 & 9.8 \\
\hline \multicolumn{3}{|l|}{ Education level } \\
\hline None & 22 & 8.0 \\
\hline Primary & 167 & 60.5 \\
\hline Secondary & 85 & 30.8 \\
\hline University & 2 & .7 \\
\hline \multicolumn{3}{|l|}{ Work experience } \\
\hline$[1-5]$ & 99 & 35.9 \\
\hline [11-15] & 115 & 41.7 \\
\hline [16-20] & 25 & 9.1 \\
\hline [6-10] & 27 & 9.8 \\
\hline$>20$ & 10 & 3.6 \\
\hline
\end{tabular}

In this study out of 276 participants 271 (98.2\%) were male, $125(45.3 \%)$ were in the age cohort category of [31-40], majority of respondent 167 $(60.5 \%)$ attended primary school and 115 (41.7\%) have a working experience that range between 11 to 15 years (Table 1$)$.

Table 2: Distribution of types of occupational Hazards identified in Integrated Craft Production Centers

\begin{tabular}{|l|c|c|c|c|}
\hline \multirow{2}{*}{} & \multicolumn{4}{|c|}{ Exposed to Hazards } \\
\cline { 2 - 5 } & Yes & \% & No & \% \\
\hline Noise exposure & 259 & 93.8 & 17 & 6.2 \\
\hline Fall of material & 248 & 89.9 & 28 & 10.1 \\
\hline Sharp machines/ equipment & 247 & 89.5 & 29 & 10.5 \\
\hline Confined space & 237 & 85.9 & 39 & 14.1 \\
\hline Slippery floor & 217 & 78.6 & 59 & 21.4 \\
\hline Manual lifting of heavy load & 188 & 68.1 & 88 & 31.9 \\
\hline Unprotected wires & 133 & 48.2 & 143 & 51.8 \\
\hline Working at height & 87 & 31.5 & 189 & 68.5 \\
\hline Chemical splash & 57 & 20.7 & 219 & 79.3 \\
\hline Contagious waste & 24 & 8.7 & 252 & 91.3 \\
\hline
\end{tabular}

The study found that out of 276 study participants $268(97.1 \%)$ are exposure to occupational hazards. The most prevalent types of occupational hazards are noise $93.8 \%$ (259/276), fall of materials $89.9 \%$ $(248 / 276)$,and use of sharp machines/equipment $89.5 \%$ (247/276). Other occupational hazards identified was working in confined space $85.9 \%$
(237/276), Slippery floor 78.6\% (217/276), Manual lifting of heavy load $68.1 \%$ (188/276). While the occupational hazards with less frequency were chemical splash $20.7 \%$ (57/276) and contagious waste $8.7 \%$ (24/276). (Table 2) 
Table 3: The Chi-square test on relationship between the prevalence of occupational hazards and risk factors

\begin{tabular}{|l|c|c|c|c|c|c|}
\hline $\begin{array}{l}\text { Factors contributing to occurrence of } \\
\text { Occupational Health Hazards }\end{array}$ & Yes & $\mathbf{\%}$ & No & $\mathbf{\%}$ & $\begin{array}{c}\text { Pearson Chi- } \\
\text { square }\end{array}$ & P-value \\
\hline Poor Infrastructure safety information & 247 & 89.5 & 29 & 10.5 & 13.665 & 0.005 \\
\hline $\begin{array}{l}\text { Poor } \\
\text { communication }\end{array}$ & 213 & 77.2 & 63 & 22.8 & 1.007 & 0.388 \\
\hline Equipment maintenance and calibration & 200 & 72.5 & 76 & 27.5 & 0.410 & 0.688 \\
\hline $\begin{array}{l}\text { Poor job supervision on the use of } \\
\text { Poor knowledge on } \\
\text { protective equipment }\end{array}$ & 178 & 64.5 & 98 & 35.5 & 2.621 & 0.137 \\
\hline A lot of work & 72.1 & 77 & 27.9 & 0.971 & 0.450 \\
\hline Lack of trainings & 146 & 52.9 & 130 & 47.1 & 2.574 & 0.154 \\
\hline Lack of complete PPE & 227 & 82.2 & 49 & 17.8 & 0.156 & 1 \\
\hline $\begin{array}{l}\text { Little knowledge on Health and safety } \\
\text { measures }\end{array}$ & 247 & 89.5 & 29 & 10.5 & 23.685 & 0.000 \\
\hline $\begin{array}{l}\text { Distraction with other issues during } \\
\text { work }\end{array}$ & 216 & 78.3 & 60 & 21.7 & 8.046 & 0.014 \\
\hline Negligence of safety procedure & 207 & 75.0 & 69 & 25.0 & 10.985 & 0.004 \\
\hline Lack of skills and experience & 226 & 81.9 & 50 & 18.1 & 5.646 & 0.038 \\
\hline Poor knowledge of job responsibilities & 210 & 76.1 & 66 & 23.9 & 11.818 & 0.003 \\
\hline
\end{tabular}

Tracing the main factors that influence the occurrence of work hazards in the Integrated Craft Production Centers through chi-square test. Factors that have a statistical significant association with occurrence of occupational hazards were; Poor infrastructure $(\mathrm{P}=0.005)$, Lack of complete Personal Protective Equipment $(\mathrm{P}=0.000)$, Little knowledge on health and safety measures $(\mathrm{P}=0.0014)$, Negligence of safety procedure $(\mathrm{P}=0.038)$, Lack of skills and experience $(\mathrm{P}=0.003)$, Distraction with other issues during work $(\mathrm{P}=0.004)$ Lack of skills and experience $(\mathrm{P}=0.003)$ and Lack of knowledge of job responsibilities $(\mathrm{P}=0.028)$. (Table 3 )

\section{Discussion}

Almost all participants in the study were male $98.2 \%$, nearly to a half (45.3\%) of participant were in the age category of $31-40$, this is similar to the findings of other occupational health studies conducted in different countries like Nepal ${ }^{13}$ and Rwanda. ${ }^{4}$ The majority of respondent $(60.5 \%)$ attended primary school; this finding differ from finding of other occupational health and safety studies done in different professions in Rwanda which showed that the majority of respondents attended tertiary education. ${ }^{4,14}$
The study findings revealed that almost all workers $(97.1 \%)$ are exposed to occupational hazards these finding are in agreement with the study conducted in Ethiopia that found that $86.5 \%$ welders were exposed to occupational hazards that might occur during the working process. ${ }^{15}$ These findings also are in agreement with studies and documents that classified professions found in Integrated Craft Production Centers mainly carpentry, welding and craft among the categories of hazardous professions. ${ }^{13,16}$

The study found that the most prevalent occupational hazard identified by participants was exposure to high noise with the highest proportion frequency of $259(93.8 \%)$. This finding are similar to the finding of a study done to assess occupational hazard exposure and general health profile of welders in rural Delhi ${ }^{17}$ as well as the findings of the same study conducted in Nepal where noise was identifeid by $75,5 \%$ responded. ${ }^{13}$ Followed by fall of materials 248 (89.9\%) which is in line with findings of the study conducted in Nairobi where hit by falling materials was identified as the main hazards that lead to injuries. ${ }^{18}$ The use of sharp machine/ equipment had a frequency of 247 (89.5\%), which confirm the findings of a study conducted in Nepal where use of sharp equipment was among the main 
occupational hazards with the prevalence of $86.7 \% .^{13}$

Other important occupational hazards identified in the study were slippery floor identified by 217 (78.6\%). Which is in agreement with findings of another study conducted in Rwanda that identified slip and fall among the main occupational hazards in Rwanda. ${ }^{4}$ In addition, this study showed that workers are exposed to hazards related to manual lifting of heavy loads since it has identified by 188 $(68.1 \%)$.

The main factors which contribute to occurrence of occupational hazards in the study included Poor Infrastructure $(\mathrm{P}=0.000)$ and Lack of Personal Protective Equipment $(\mathrm{P}=0.005)$. Which is in agreement with studies conducted to determine the prevalence of injuries in Ethiopia. ${ }^{19,20}$

Moreover, individual factors that have a significant relationship with occurrence of occupational hazards were negligence at work $(\mathrm{P}=0.038)$, lack of skills and experience of employees $(\mathrm{P}=0.001)$, as well as poor knowledge of job responsibilities $(\mathrm{P}=0.028)$. These findings confirm results of a similar study conducted in Rwanda that concluded that individual factors contribute to existence of work hazards. ${ }^{11}$

\section{Conclusion}

According to the study findings, it is clear that workers are exposed to work hazards that can lead to occupational accidents and diseases but they are not effectively reported since there is no formal reporting system in place. Thus, they should be establishment of occupational health and safety trainings and awareness campaign to improve the knowledge of workers with regard to the prevention of occupational hazards. There is a need of enforcing the use of Personal Protective Equipment, improve safety communication and establish a proper reporting system of occupational hazards.

\section{References}
1. Ahmad I, Sattar A, Nawaz A. "Occupational health and safety in

industries in developing world" Gomal Journal of Medical Sciences 2016; 14:2238

2. Jukka T, Päivi H, Kaija LS, Loke YY, Kathiresan M, Tan WJ, Peggy H, Caleb T, Lim GK, Samuel L, Gan SL. Global Estimates of the Burden of Injury and Illness at Work in 2012 Journal of Occupational and Environmental Hygiene, 2014

3. Muhammad IK. Developing a Safety Culture in Developing Countries, 2013

4. Eduard M. To Assess the Prevalence of Occupational Health Related Risks and Use of Safety Measures among Employees in Bralirwa Processing Industries. Occup Med Health Aff 2015, 3:52015 http://dx.doi.org/10.4172/23296879.1000215

5. Noora nenonen, KL.Global estmates of occupational accident and work related illnessWorkplace Safety \& Health Institute, 2014

6. Alice B, Tony Z. Guillermo $\mathrm{H}$. Occupational Health and safety risks for the most vulnerable workers, 2011. Directorate general for internal policies policy department a: economic and scientific policy employment and social affairs Retrieved from https://eige.europa.eu/docs/2024_IPOLEMPL_ET(2011)464436_EN.pdf

7. Health and Safety Executive. (2019). Health and safety at work Health Summary statistics for Great Britain 2019. Health and Safety Executive. Retrieved from www.hse.gov.uk/statistics/about/

8. International Labour Organisation. Safety and health at work: A vision for sustainable prevention. World congress on safety and health 2014. frankfurt, Germany

9. Iraj M, Mojtaba K, Mansour M, Rostam G, Yadollah H, Alireza S. Evaluation of the Quality of Occupational Health and Safety 
management system based on key perfomence in certified organization. Safety and Health at Work 8 2017; 156e161. doi: 10.1016/j.shaw.2016.09.001

10. Ministry of Public Service and Labour, Occupational Health and Safety Policy 2014.

11. Chinenye M N, Simon K, Hilda V. Occurrence of occupational health hazards in districts health facilities in Kigali, Rwanda, International Journal of Community Medicine and Public Health. 2018; doi:http://dx.doi.org/10.18203/23946040.ijcmph20175509

12. Kagera, T. National Employment Program - "Kora Wigire" gradually brings new jobs in reach. 2016

13. Shyam, SB, Suman, BS, Reshu AS, Surya RN. Awareness of occupational hazards and use of safety measures among welders: A cross-sectional study from eastern Nepal, $\quad B M J \quad 2014 ; \quad$ doi: doi:10.1136/bmjopen-2013-004646

14. Jotham K, Noel K., David B, Innocent H, Marie Claire I, Mecthilde M, Isabelle K, Emelyne, UC, Liliane B, Charite, N, Abela AM. Occupational Health Risks Associated with Medical Waste Management Practices among Health Professionals Working in Three District Hospitals in Rwanda, Rwanda Journal of Medicine and Health Sciences Vol. 2 No.3, 2019; https://dx.doi.org/10.4314/rjmhs.v2i3.7

15. Sebsibe T, Kassahun B, Bikes D, Yalemzewod A. Awareness of occupational hazards and associated factors among welders in Lideta Sub-City, Addis Ababa, Ethiopia,. Journal of Occupational Medicine and Toxicology. 2016; doi:10.1186/s12995-016-0105-x.

16. European Accreditation. EA - 3/13 EA Document on the Application of ISO/IEC 17021-1 for the Certification of
Occupational Health and Safety Management Systems (OH\&SMS), 2016

17. Anuradha C, Tanu A, Jugal K, Erik TD, Gopal KI. Occupational hazard exposure and general health profile of welders in rural Delhi. Indian Journal of occupational and environmental medicine. Volume 18 Issue Page 21-26 2014; doi: 10.4103/0019-5278.134953,

18. Kemei R, Charles K, James WK. Common Construction Site Hazards in Nairobi County Kenya. American Journal of Construction and Building Materials, 2017; 2, 70-77. doi:doi: 10.11648/j.ajcbm.20170203.11

19. Getnet AM., Waju BS, Yohannes KL. Prevalence and determinants of work related injuries among small and medium scale industry workers in Bahir Dar Town, north west Ethiopia" Annals of Occupational and Environmental Medicine. 2015; doi:DOI 10.1186/s40557-015-0062-3;.

20. Asrat M, Bezuayehu A, Andualem H. Work Related Injuries and Associated Factors among Small Scale Industry Workers of Mizan-Aman Town, Bench Maji Zone, Southwest Ethiopia" Ethiopian Journal of. Health Development. 2017; 31(3). 